\title{
LUPUS MENINGOENCEPHALITIS CAUSING UNUSUALLY GLUCOSE CONSUMED IN CEREBROSPINAL FLUID
}

Victor Pereira Mattos1, ${ }^{*}$, Gustavo Luiz Behrens Pinto1, Mariana Oliveira Miranda1, Adriane Souza da Paz1, Viviane Leal Novais1, Mittermayer Barreto Santiago1

1.Universidade Federal da Bahia, Salvador (BA), Brazil.

*Corresponding author: victor_mattos@outlook.com.br

\section{BACKGROUND}

Systemic lupus erythematosus (SLE) is a systemic autoimmune disease characterized by articular, cutaneous and visceral manifestations, presence of autoantibodies against nuclear antigens, consumption of complement and formation of immune complexes. Aseptic meningitis associated with SLE is an uncommon and poorly described manifestation. The authors report the case of a patient with SLE with aseptic meningitis.

\section{CASE REPORT}

Afemale patient, 18years old, diagnosed with SLE (cutaneous, articulate, hematological and serositis) since2018, using hydroxychloroquine and azathioprine, was admitted to the hospital in March 2019 with headache and vomiting. She performed a computed tomography (CT) scan of the skull that showed no changes, and a lumbar puncture with a cerebral spinal fluid (CSF) study revealing hypoglycorrhea $(<5 \mathrm{mg} / \mathrm{dL})$, hyperproteinorrhachia (186 mg/dL) and pleocytosis (117 cells) with a predominance of lymphocytes ( $83 \%$ ), with negative culture for pyogenic, mycobacteria and fungi. She received empirical treatment for meningeal tuberculosis with rifampicin, isoniazid, pyrazinamide, ethambutol and dexamethasone for 9 months, with improvement of the condition, but she discontinued follow-up and abandoned the treatment in March 2020. In July 2020, the patient was readmitted with headache, vomiting and severe low back pain. On physical examination, she had stiff neck and a positive Lasègue sign. Study of CSF presented characteristics similar to the previous one and the measurement of the opening pressure increased $(30 \mathrm{mmHg}$ ). She performed neuroaxis MRI with diffuse leptomeningeal contrast enhancement in the skull and spine (Figs. 1 and 2). The biopsy of dura mater ruled out central nervous system (CNS) lymphoma and the search for fungi and mycobacteria were negative. Prednisone $1 \mathrm{mg} / \mathrm{kg}$ was restarted with complete improvement of complaints. New CSF was collected before discharge with protein $87 \mathrm{mg} / \mathrm{dL}$, glucose $19 \mathrm{mg} / \mathrm{dL}$ and 36 cells ( $98 \%$ lymphocytes).

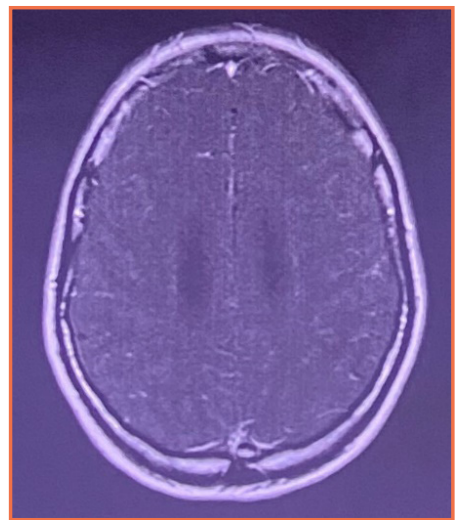

Figure 1

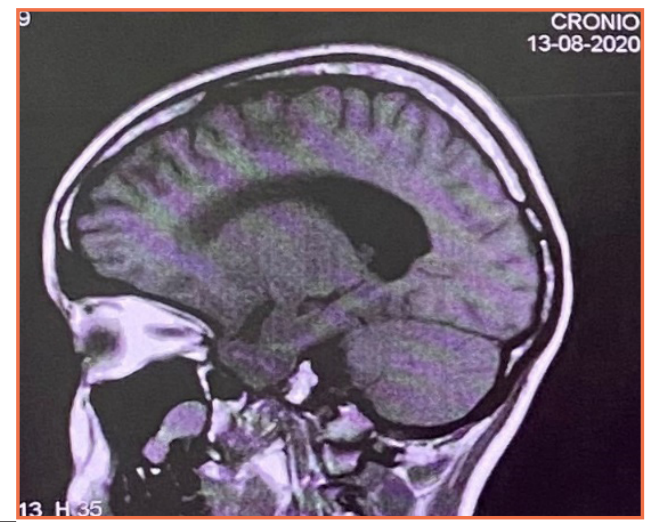

Figure 2

\section{CONCLUSION}

Aseptic meningitis is a rare condition in SLE $(<1 \%)$. Changes in CSF include lymphocytic pleocytosis with a count generally less than 200 cells $/ \mathrm{mm}^{3}$, hyperproteinorrhachia usually less than $100 \mathrm{mg} / \mathrm{dL}$ and normal glucose. Among patients with SLE and CNS involvement, less than $4 \%$ have a slight reduction in glucose in CSF. The neurological manifestation most related to CSF glucose levels is transverse myelitis. We report the case of a patient with lymphocytic meningitis secondary to SLE with severe hypoglycorrhea with improvement after immunosuppression. 
